\title{
Minimally invasive therapy of epiphrenic diverticula: Systematic review of the literature and report of 6 cases
}

\author{
Mariel Gonzalez-Calatayud, Eduardo M. Targarona, Carmen Balague, \\ Carlos Rodriguez-Luppi, Ana B. Martin, Manuel Trias \\ Department of General Surgery, Hospital de la Santa Creu I Sant Pau UAB, Barcelona, Spain
}

\begin{abstract}
Epiphrenic diverticula is an uncommon disease, and conventional surgical treatment entails aggressive open or transthoracic surgery. Minimally invasive treatment has changed the surgical approach, but a number of surgical controversies remain unresolved. The present study is a description of our experience with minimally invasive treatment of epiphrenic diverticula and a systematic review of the current literature on this subject. All data from the Hospital de Sant Pau were reviewed to identify patients who underwent minimally invasive treatment for epiphrenic diverticulum since 1998. In addition, systematic literature review focused on minimally invasive approach for epiphrenic diverticula was performed. Total of 6 patients have been treated ( 6 transhiatal and 1 with abdominal and thoracic approach) at the hospital. Predominance of male patients was observed, with median age of 63 years. Diagnosis was made with endoscopy, barium swallow, or manometry. Half of manometry results where pathological. Surgical techniques applied were diverticulectomy, myotomy, and Dor partial fundoplication. Two patients with suture line leakage were treated conservatively. No mortality was reported. Systematic literature review was conducted using the PRISMA scheme, and 21 studies with 189 patients were found. No comparative or prospective randomized trials were located. Overall morbidity rate was $24 \%$, suture line leakage rate was $12 \%$, hospital stay was 5 days, and mortality rate of $1.5 \%$ in the literature. After median follow up of 42 months, $81.5 \%$ of the patients were asymptomatic. Minimally invasive approach for epiphrenic diverticula is a safe and feasible procedure.
\end{abstract}

Keywords: Epiphrenic diverticula; esophageal diverticulum; minimally invasive surgery.

\section{Introduction}

Epiphrenic diverticula is a rare condition with an unknown incidence. ${ }^{[1,2]}$ There is an estimated prevalence of $0.015 \%$ in the United States, $0.77 \%$ in Japan and up to $2 \%$ in Europe. ${ }^{[3-8]}$ In 1998, Rosati et al. ${ }^{[9]}$ was the first surgeon to perform a minimally invasive transhiatal access for epiphrenic diverticulum (ED) on a patient.

Most of the authors recommend surgical treatment when a diverticulum becomes symptomatic, disabling or associated with atypical symptoms such as pulmonary pathology. ${ }^{[10-13]}$

Nowadays, there is no consensus on the type of surgical access, the length of the myotomy or the type of antirefl ux technique..$^{[1,7,14,16-21]}$ The conventional surgical procedure that was usually performed consisted a left thoracotomy, di- 
verticulectomy, myotomy and a Belsey Mark IV procedure, nonetheless, this treatment implicates a non-negligible morbidity rate reaching up to $20-25 \%$ of patients, the most important one being suture line leakage and a mortality up $5 \%$. ${ }^{[22]}$ These results and the good access to the hiatal hiatus obtained through a minimally invasive technique has favoured during last years to switch to endoscopic surgery. However, the scarce incidence of this procedure difficult to obtain definitive data from large series of the performance of randomiced trials, and justifies to present the outcome of shorter series or to analyze the pooled results of different experiences using a systematic methodology.

The objective of this study is to describe our experience with the minimally invasive surgical treatment of the ED and to systematically review the current knowledge about treating ED with an endoscopic access.

\section{Materials and Methods}

\section{Cases Report}

We retrospectively reviewed the medical records of patients that underwent minimally invasive access surgery for epiphrenic diverticulum in the database of the Hospital de la Santa CreuiSant Pau, from 1998 to date. The variables that we analyzed were preoperative characteristics (age, gender), preoperative work up type of surgery, postoperative complications, length of hospital stay and follow up.

Minimally invasive transhiatal approach technique: The abdomen is approached with five trocars located as is conventionally for upper abdominal surgery. We start with the dissection of the gastrohepatic ligament using a harmonic scalpel, and continue until we find the right diaphragmatic pillar, with a complete dissection of the phrenoesophageal ligament and the circumference of the gastroesophageal junction. A Pinotti's maneuver (section of the hiatus) is performed selectively according to the size of the hiatus. Afterwards, we mobilize the lower esophagus extensively to identify the diverticulum. Dissection is performed combining blunt, electrocautery or harmonic energy, till the neck of the ED is reached at submucosal level.Once the diverticulum is released, we expose the diverticular neck and it is severed with a linear stapler. Then, the suture line integrity is confirmed endoscopically and/or by methylene blue. The next step is to proceed with an anterior myotomy of the esophagus, beginning at the upper level of the neck transection, and the myotomy ends after $1.5-2 \mathrm{~cm}$ caudal into the gastric wall. The last step is a partial Dor fundoplication. Weput systematically a mediastinal drain. Forty eight hours after the procedure, a gastrografin swallow is performed before starting the oral intake.

\section{Systematic Review}

Search strategy: This systematic review of literature was performed according to the recommendations published in the consensus document "Preferred Reporting Items for Systematic Reviews and Meta-Analyses (PRISMA)". [23]

The electronic search was conducted in the PubMed database using the following terms: "diverticulectomy", "minimally invasive diverticulectomy", "surgical treatment for epiphrenic diverticula", "surgical treatment for epiphrenic diverticulum”, "laparoscopic diverticulectomy epiphrenic”, "epiphrenic diverticulectomy", “esophageal diverticulum" and "tratamientolaparoscópico de divertículoepifrénico".

The search was performed restricting language to English and Spanish.

\section{Inclusion Criteria}

- Clinical studies including minimally invasive transhiatal diverticulectomy, either with laparoscopic access or robotic-assisted,

- Articles that study both techniques (transhiatal and thoracoscopy), in which the transhiatal approach was used in more than $50 \%$ of the patients under study,

- Studies which specifically describe the preoperative characteristics, diagnostic method, surgical technique, complications and follow-up.

Exclusion criteria: We excluded studies using open approaches (thoracotomy) or thoracoscopy in more than $50 \%$ of the population. We also ignored all studies that did not fulfill the criteria described.

Data collection: We reviewed the full text of the articles obtained based on the above search strategy. The data collected included the author's name, time of study, population demographics, preoperative characteristics, perioperative data, postoperative complications and follow up.

\section{Results}

\section{Case Report}

Since 1998 to dae we operated 6 patients in our center. 
Clinical features of the patients are plotted in Table 1. We performed transhiatal treatment in 5 of those patients. On the other patient, that presented an ED and hiatal hernia and GERD we used a combined technique. Initially, a transabdominal approach was performed, but the ED was too high for an abdominal access, and then, a hiatal closure and a partial (Toupet) wrap wqs performed. In a second procedure a video assisted thoracoscopic resection was performed. Operative time ranged between 180 and 210 minutes, with minimal intraoperative bleeding (30$100 \mathrm{~mL}$ ). Two patients had postoperative suture line leakage, one of them during the first 48 hours. In other case, the patient was readmitted ten days after an uneventful recovery due to thoracic pain and a minimal leakage was observed. The patient was treatd conservatively with diet and antibiotics, evolving uneventfully (Table 1, Figure 1). Five of the 6 patients are asymptomatic after mean follow up of 62 months (1-180), and one patient developed dysphagia due to a pseudodiverticulum at the myotomy site.

\section{Literature Review}

We found 56 articles related to the treatment for epiphrenic diverticulum in PubMed. Only 20 publications met the inclusion criteria. A total of 189 patients were reported including our 6 cases (Figure 2).

Preoperative characteristics: Of the 189 patients, there were 95 men and 94 women, with a mean age of 61 (27-96) and a weighted average of 51.3 months for the duration of symptoms before surgery. The predominant preoperative symptoms were: dysphagia, followed by regurgitation, chest pain, heartburn, weight loss and less frequent atypical respiratory symptoms. The diagnoses were made

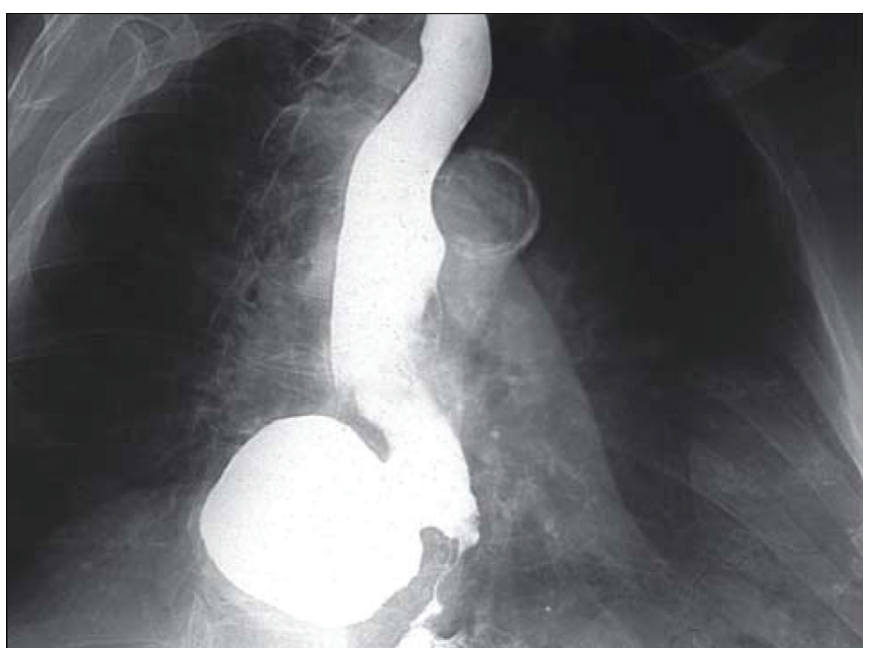

Figure 1. Pre-operative Barium swallow of patient number 4 .

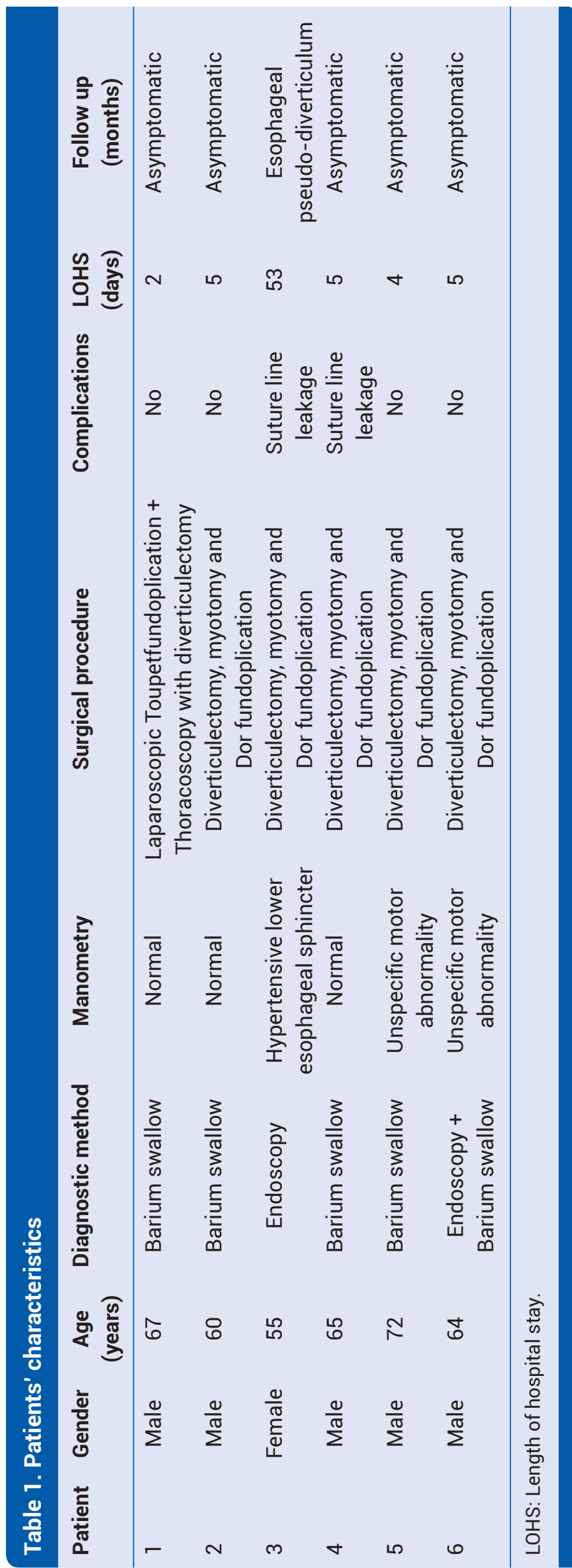


by barium swallow, endoscopy and manometry in $90 \%$ of the publications. In addition, some authors included $\mathrm{pH}$ monitoring and computed tomography (CT). The average size of the diverticula was $5.5 \mathrm{~cm}$ (1.2 to 11) and was associated with an esophageal motility disorder in $60 \%$ of patients, the most frequent being achalasia, nutcracker esophagus and nonspecific esophageal motor disorder. The weighted average of the operative time was 120.6 minutes (106-313), however, this measurement was only reported by 13 authors. The intraoperative bleeding was minimum (30-250 mL) (Table 2).

Diverticulum management: There were 174 laparoscopic transhiatal approaches, 9 cases by thoracoscopy, 3 cases of robot-assisted transhiatal surgery and 3 mixed (abdominal and thoracic approach). 184 diverticulectomies were made (97.3\%) with the use of linear stapler, after which some authors performed suture reinforcement with non-absorbable continuous suture or placement of fibrin in the suture line. Two authors did a diverticulum inversion in a total of 5 patients (Table 2).

Myotomy: $90 \%$ of the authors performed myotomyin a total of 170 patients, $61 \%$ extended to stomach between 1 and $2 \mathrm{~cm}$, but Soares ${ }^{[17]}$ did the myotomy only in the diverticular neck with 5.2\% leakage rate (Table 2).

Fundoplication: $92.5 \%(\mathrm{n}=175)$ of patients had fundoplication associated with the surgery, $87.5 \%$ were partial (Toupet $42.5 \%$ and Dor 45\%) followed by Nissen $11.5 \%$ and $1.1 \%$ with Collis technique. Rosati et al. ${ }^{[1]}$ prefer the Dor fundoplication for GERD patients and Toupet for those who did not have it; and Klaus ${ }^{[14]}$ Nissen for those with normal motility and Toupet for abnormal ones. Tedesco ${ }^{[16]}$ is in favor of the Dor fundoplication in all patients and Fernando ${ }^{[25]}$ only in patients with a history of GERD, hiatal hernia or wide hiatal dissection. Palanivelu ${ }^{[29]}$ uses Nissen fundoplication in patients with GERD and / or hiatal hernia, Toupet technique for those with achalasia, and Dor for everyone else (Table 2).

Postoperative features: The average of the length of hospital stay was 5.1 days (1-56). There were 6 conversions to open surgery because of firm adhesions ( 2 cases) and diverticula in the mid esophagus ( 4 cases). The morbidity was $24 \%$ with a leakage rate of $11.7 \%$. Other complications

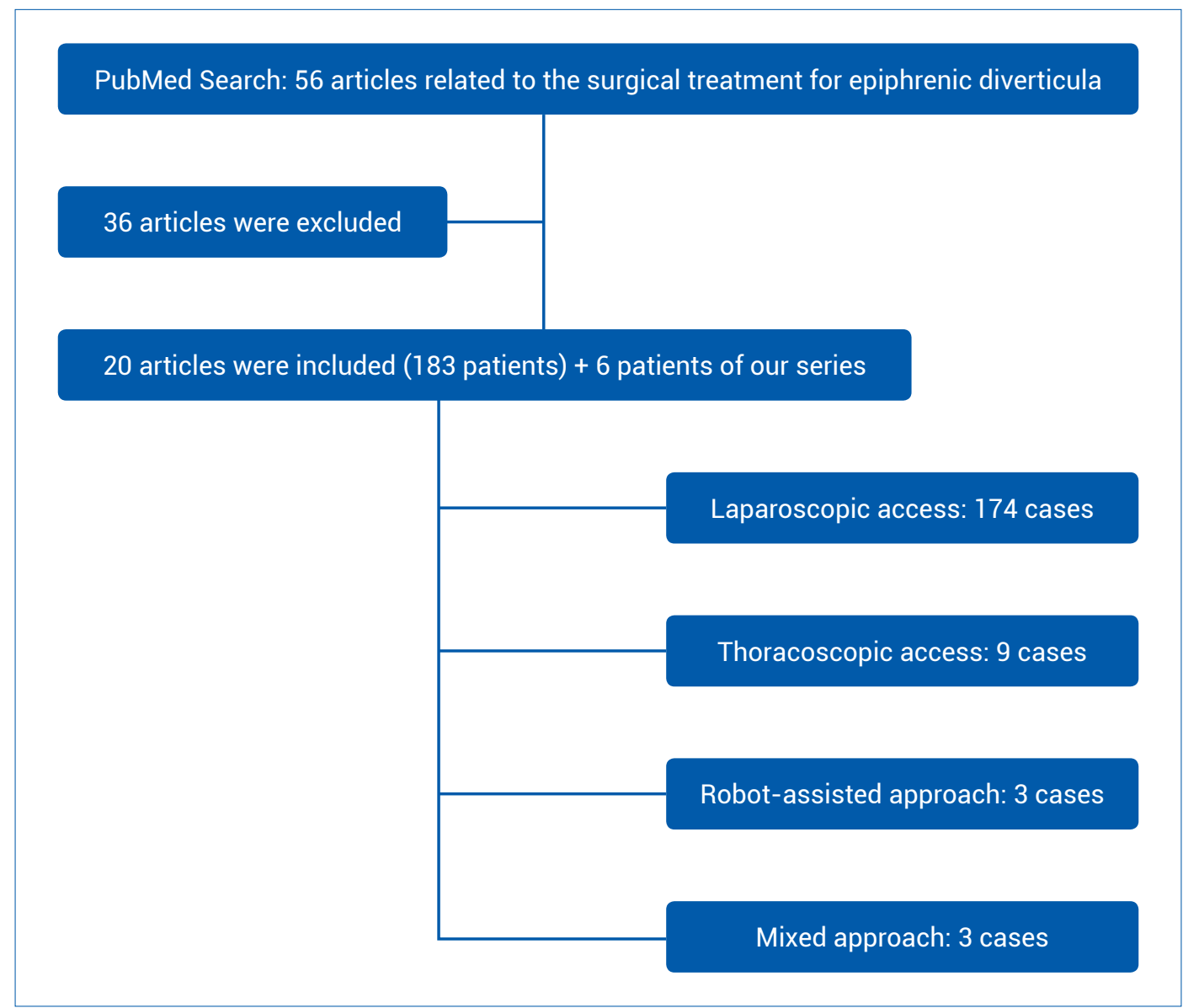

Figure 2. Flow chart of the literature review including the patients of our series. 


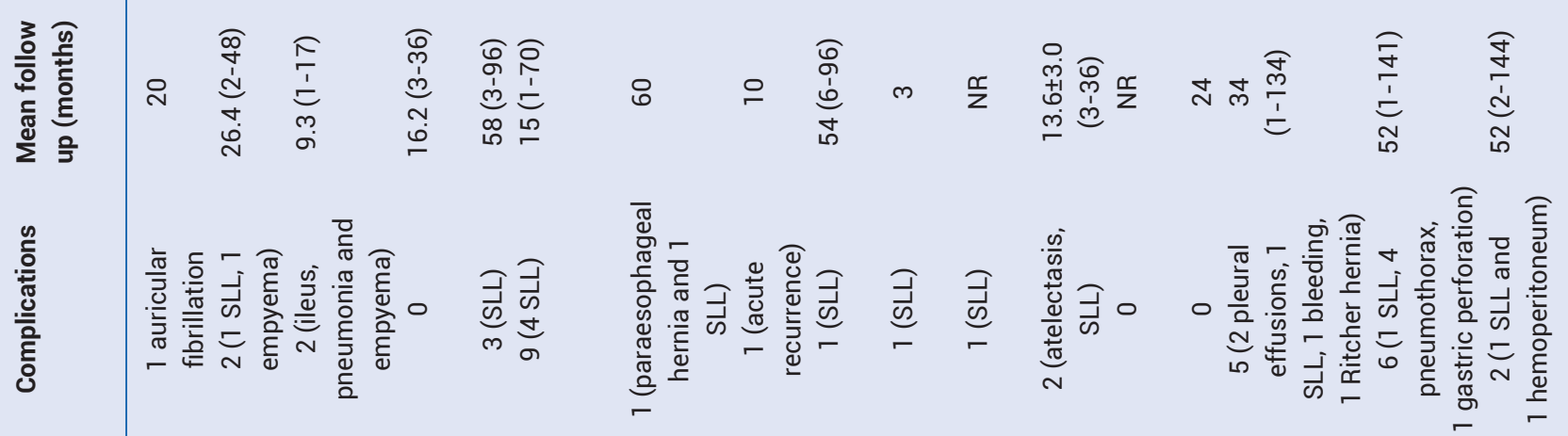

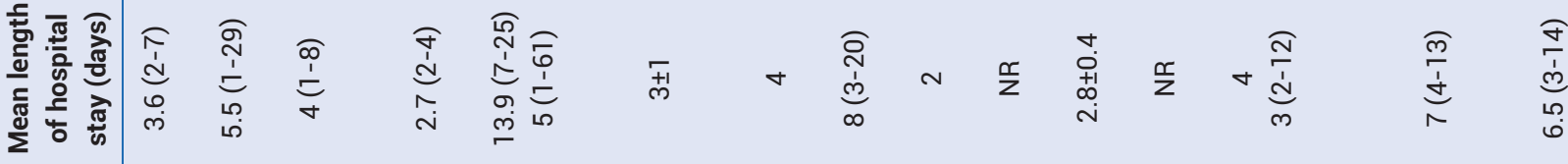

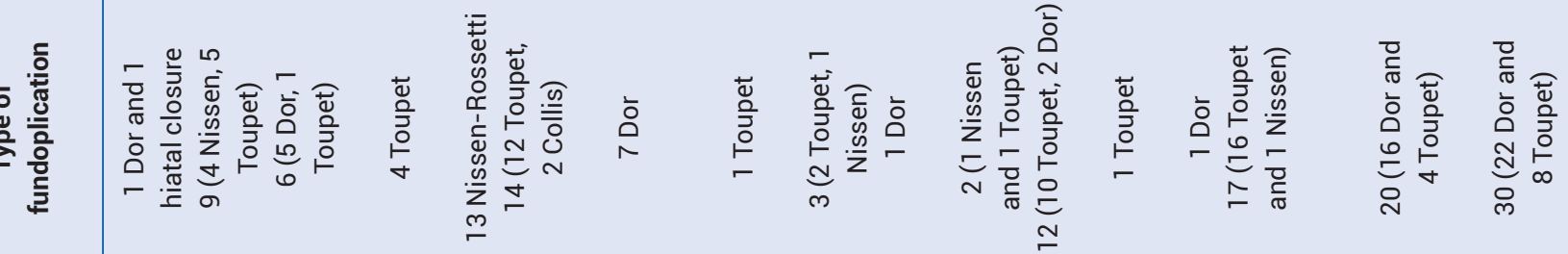

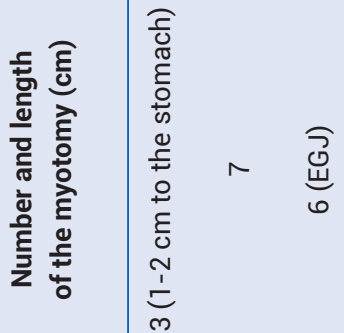

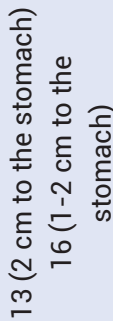

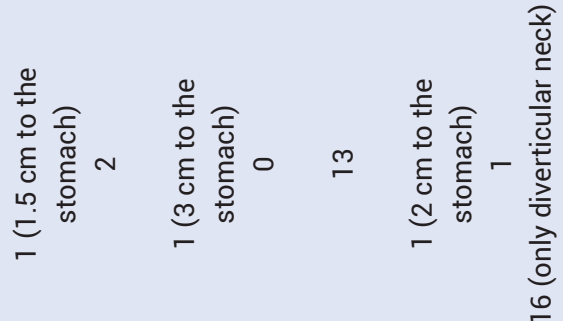

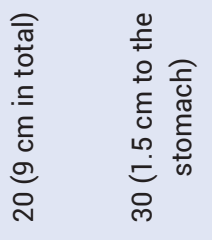

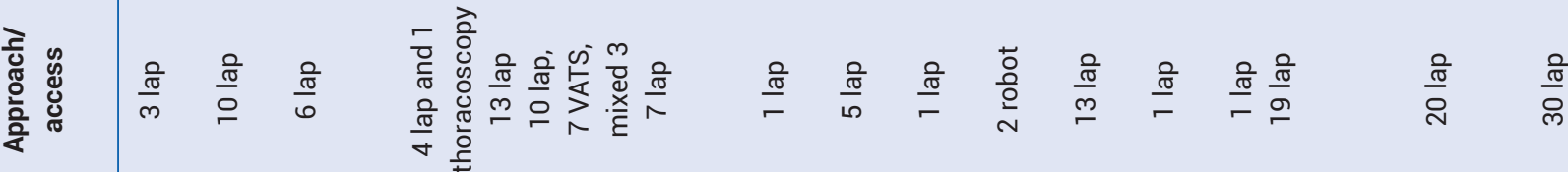

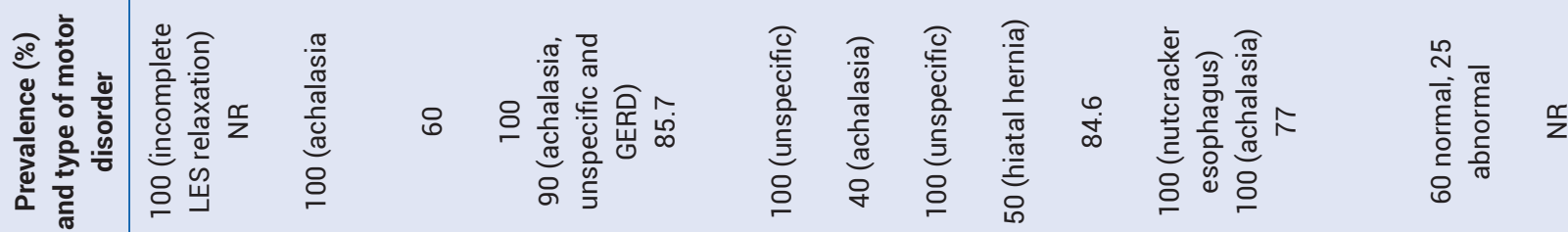

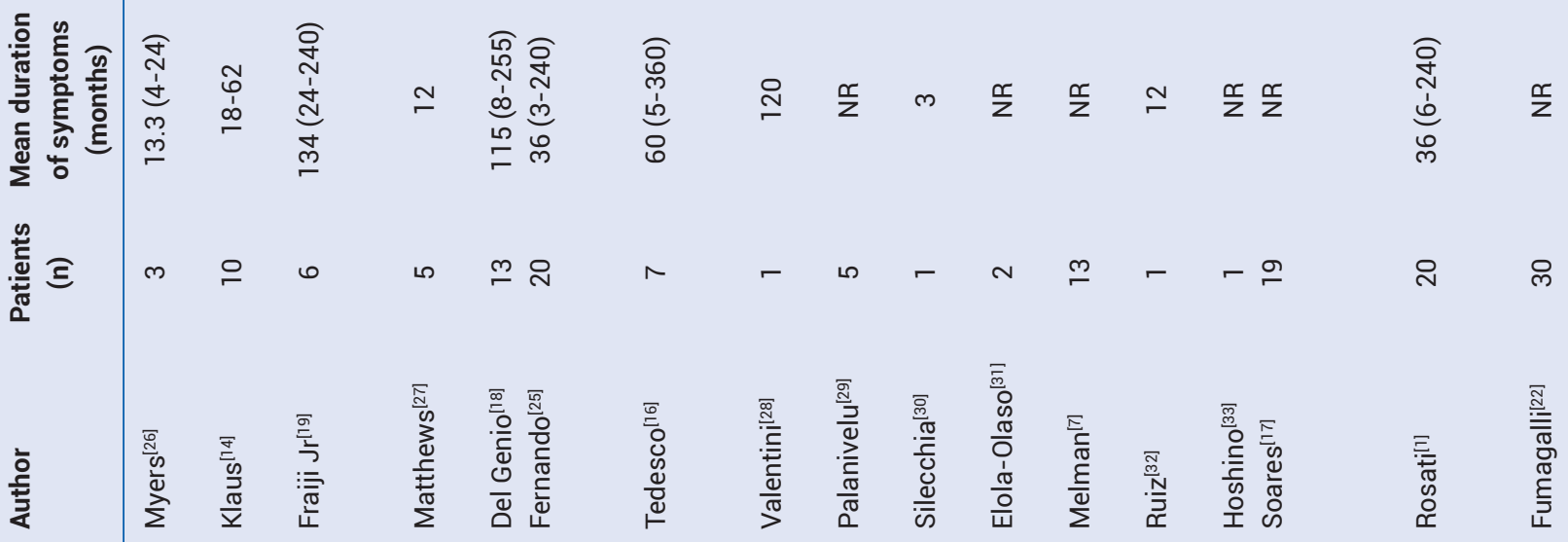




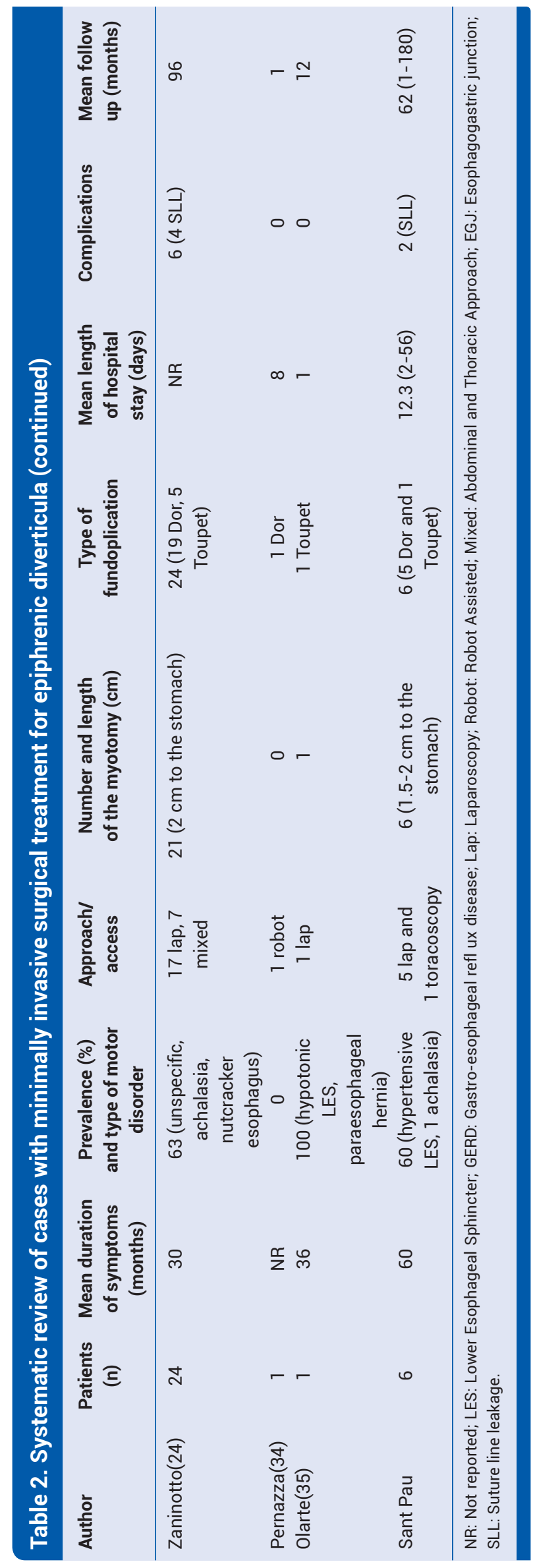

included acute recurrence, empyema, paraesophageal hernia, Ritcher hernia, pneumothorax, atelectasis, pleural effusion and bleeding.

Fourteen patients had to undergo further surgeries $(8 \%)$ of which $75 \%$ were due to suture dehiscence. The mortality rate was 1.5\% (1 strangulated hernia, 1 suture line leak and one more for acute myocardial infarction). The weighed average for the postoperative follow-up was 42.4 months (1-96 months) in which $81.5 \%$ of patients were reported asymptomatic, $13.4 \%$ presented mild symptoms treated medically, and only $5 \%$ had severe symptoms that required invasive treatment or conservative medical treatment with poor results. The reported recurrence average is $2.2 \%$ (Table 2 ).

\section{Discussion}

Epiphrenic diverticula occur in the distal esophagus and only $15-20 \%$ are symptomatic. Benacci et al. ${ }^{[39]}$ reported that patients with asymptomatic or mild symptoms do not require surgical treatment because $100 \%$ of their series showed no symptomatic progression; conversely, authors like Altorki et al. ${ }^{[40]}$ are in favor of surgical treatment in all patients to prevent respiratory complications.

Currently, minimally invasive surgery has presented excellent results in this situations with a symptomatic improvement of $85-100 \%$, suture leakage rate of $8-23 \%, 8-10 \%$ of pulmonary complications and a mortality of $0-7 \% \cdot{ }^{[3,17]}$ It appears that the advantages of the minimally invasive approach include: easy access, improved visualization, proper stapling line, possibility of myotomy and antirefl ux technique, along with the possibility of treating any complication during the surgery. In addition, there is a shorter hospital stay and minimal analgesia requirements. The disadvantages that have been described are: the difficulty of dissection for large diverticula or diverticula that are located in the mid esophagus, and the rupture of the pleura with subsequent pneumothorax ${ }^{[4]}$ Pernazza et al. ${ }^{[34]}$ state that these disadvantages can be avoided with the use of the Da Vinci Surgical System robot with the stereoscopic endoscope, the articulation of the instruments and 3D vision.

The use and length of the myotomy is controversial. The literature describes $n$ increased leakage and recurrence rate when myotomy is not performed concomitantly. ${ }^{[3]}$

Myotomy was proposed, originally by Efl erin 1959 and Belsyin $1966,{ }^{[37]}$ and its utiity was confirmed by Nehra ${ }^{[38]}$ in 2002 since heobserved the existence of a motility disorders in $71 \%$ of patients when performing a stationary manometry, that increase to $100 \%$ with the ambulatory 24 hours manometry in patients 
with epiphrenic diverticula. From the surgical point of view, the myotomy is performed on the contralateral wall of the diverticulum, covering the complete length of the diverticular neck. In the Mayo Clinic study with 21 patients, a high incidence of leakage and recurrence $(24 \%$ and $19 \%$ respectively) was shown when performing the diverticulectomy without myotomy, compared with an associated myotomy ( $\% \%$ for both). ${ }^{[21]}$

The incidence of GERD after a myotomy can reach approximately $50 \%$, hence a fundoplication is preferred for all patients with myotomy. ${ }^{[2]}$ The controversy is related to the type of fundoplication, to avoid an hyperpressive lower esophageal sphincter that may favour staple line leakage.

Nehra et al. ${ }^{[38]}$ propose performed Nissen fundoplication in patients with normal esophageal motility and Toupet for abnormal ones. Del Genio et al. ${ }^{[18]}$ performed Nissen-Rossetti fundoplication with an incidence of leakage of $23 \%$, and therefore they recommend a transoperative manometry to verify the lower esophageal sphincter pressure. In Japan, the Dor fundoplication it is recommended because it is easier to perform and can potentially prevent the formation of a pseudodiverticulum or leakage if an intraoperative esophageal mucosa perforation occurs. ${ }^{[40]}$

Regarding the complications rate, Rosati et al. ${ }^{[1]}$ associated the risk of suture line leakage with the size of the diverticulum (more than $9 \mathrm{~cm}$ ) and Zaninotto et al. ${ }^{[24]}$ with the use of more than one stapling shot.

In our experience, we prefer to perform the diverticulectomy, a long myotomy extended to the gastric wall and an anterior Dor partial fundoplication because we believe that esophageal motor disorder is the cause of diverticula, just as Nehra reported. ${ }^{[38]}$ The Dor fundoplication not only prevents postoperative gastroesophageal refl ux, but it also protects the myotomy. Despite these considerations, it is noteworthy that two of our patients had a suture line leakage that were treated conservatively and one of them was diagnosed with a pseudodiverticulum one year after surgery with normal manometry which could be explained by intense fibrosis, fundoplication failure or incomplete myotomy.

Minimally invasive surgery for the treatment of epiphrenic diverticula is reliable with satisfactory results similar to those reported in the literature with the standard technique. It is difficult to perform prospective randomized studies because of the rarity of the disease; however, we consider that the minimally invasive surgery is the tech- nique of choice for the surgical treatment of the epiphrenic diverticula.

\section{References}

1. Rosati R, Fumagalli U, Elmore U, de Pascale S, Massaron S, Peracchia A. Long-term results of minimally invasive surgery for symptomatic epiphrenic diverticulum. Am J Surg 2011;201:132-5.

2. Ruiz De Angulo Martín D, Ortiz Escandell MA, Martínez De Haro LF, Munítiz Ruiz V, Parrilla Paricio P. Epiphrenic diverticula: when and how to operate? Cir Esp 2009;85:196-204.

3. Herbella FA, Patti MG. Modern pathophysiology and treatment of esophageal diverticula. Langenbecks Arch Surg 2012;397:29-35.

5. Dobashi Y, Goseki N, Inutake Y, Kawano T, Endou M, Nemoto T. Giant epiphrenic diverticulum with achalasia occurring 20 years after Heller's operation. J Gastroenterol 1996;31:8447.

6. Schima W, Schober E, Stacher G, Franz P, Uranitsch K, Pokieser $\mathrm{P}$, et al. Association of midoesophageal diverticula with oesophageal motor disorders. Videofluoroscopy and manometry. Acta Radiol 1997;38:108-14.

7. Melman L, Quinlan J, Robertson B, Brunt LM, Halpin VJ, Eagon JC, et al. Esophageal manometric characteristics and outcomes for laparoscopic esophageal diverticulectomy, myotomy, and partial fundoplication for epiphrenic diverticula. Surg Endosc 2009;23:1337-41.

8. Borrie J, Wilson RL. Oesophageal diverticula: principles of management and appraisal of classification. Thorax 1980;35:759-67.

9. Rosati R, Fumagalli U, Bona S, Zago M, Celotti S, Bisagni P, et al. Laparoscopic treatment of epiphrenic diverticula. J Laparoendosc Adv Surg Tech A 2001;11:371-5.

10. Jordan PH Jr, Kinner BM. New look at epiphrenic diverticula. World J Surg 1999;23:147-52.

11. Benacci JC, Deschamps C, Trastek VF, Allen MS, Daly RC, Pairolero PC. Epiphrenic diverticulum: results of surgical treatment. Ann Thorac Surg 1993;55:1109-13.

12. Zaninotto G, Rizzetto C, Zambon P, Guzzinati S, Finotti E, Costantini M. Long-term outcome and risk of oesophageal cancer after surgery for achalasia. Br J Surg 2008;95:1488-94.

13. Castrucci G, Porziella V, Granone PL, Picciocchi A. Tailored surgery for esophageal body diverticula. Eur J Cardiothorac Surg 1998; 14:380-7.

14. Klaus A, Hinder RA, Swain J, Achem SR. Management of epiphrenic diverticula. J Gastrointest Surg 2003;7:906-11.

15. Kilic A, Schuchert MJ, Awais O, Luketich JD, Landreneau RJ. Surgical management of epiphrenic diverticula in the minimally invasive era. JSLS 2009;13:160-4.

16. Tedesco P, Fisichella PM, Way LW, Patti MG. Cause and treatment of epiphrenic diverticula. Am J Surg 2005;190:891-4.

17. Soares RV, Montenovo M, Pellegrini CA, Oelschlager BK. Laparoscopy as the initial approach for epiphrenic diverticula. Surg Endosc 2011;25:3740-6. 
18. Del Genio A, Rossetti G, Maffetton V, Renzi A, Brusciano L, Limongelli $P$, et al. Laparoscopic approach in the treatment of epiphrenic diverticula: long-term results. Surg Endosc 2004; 18:741-5.

19. Fraiji E Jr, Bloomston M, Carey L, Zervos E, Goldin S, Banasiak $M$, et al. Laparoscopic management of symptomatic achalasia associated with epiphrenic diverticulum. Surg Endosc 2003;17:1600-3.

20. Eubanks TR, Pellegrini CA. Minimally invasive treatment of esophageal diverticula. Semin Thorac Cardiovasc Surg 1999;11:363-7.

21. Zaninotto G, Portale G, Costantini M, Zanatta L, Salvador $\mathrm{R}$, Ruol A. Therapeutic strategies for epiphrenic diverticula: systematic review. World J Surg 2011;35:1447-53.

22. Fumagalli Romario U, Ceolin M, Porta M, Rosati R. Laparoscopic repair of epiphrenic diverticulum. Semin Thorac Cardiovasc Surg 2012;24:213-7.

23. Moher D, Liberati A, Tetzlaff J, Altman DG; PRISMA Group. Preferred reporting items for systematic reviews and meta-analyses: the PRISMA statement. Ann Intern Med 2009;151:264-9.

24. Zaninotto $G$, Parise $P$, Salvador $R$, Costantini $M$, Zanatta $L$, Rella A, et al. Laparoscopic repair of epiphrenic diverticulum. Semin Thorac Cardiovasc Surg 2012;24:218-22.

25. Fernando HC, Luketich JD, Samphire J, Alvelo-Rivera M, Christie NA, Buenaventura PO, et al. Minimally invasive operation for esophageal diverticula. Ann Thorac Surg 2005;80:2076-80.

26. Myers BS, Dempsey DT. Laparoscopic resection of esophageal epiphrenic diverticulum. J Laparoendosc Adv Surg Tech A 1998;8:201-7.

27. Matthews BD, Nelms CD, Lohr CE, Harold KL, Kercher KW, Heniford BT. Minimally invasive management of epiphrenic esophageal diverticula. Am Surg 2003;69:465-70.

28. Valentini M, Pera M, Vidal O, Lacima G, Belda J, de Lacy AM. Incomplete esophageal myotomy and early recurrence of an epiphrenic diverticulum. Dis Esophagus 2005;18:64-6.

29. Palanivelu C, Rangarajan M, John SJ, Parthasarathi R, Senthilkumar R. Laparoscopic transhiatal approach for benign supra-diaphragmatic lesions of the esophagus: a replacement for thoracoscopy? Dis Esophagus 2008;21:176-80.

30. Silecchia G, Casella G, Recchia CL, Bianchi E, Lomartire N. Laparoscopic transhiatal treatment of large epiphrenic esophageal diverticulum. JSLS 2008;12:104-8.

31. Elola-Olaso AM, Mullett TW, Gagliardi RJ. Epiphrenic diverticulum: robotic-assisted transhiatal approach. Surg Laparosc Endosc Percutan Tech 2009;19:e184-8.

32. Ruiz J, Castillo A, González L, Barinaga R, Maldonado A, Cornejo A, et al. Esófago en cascanueces y divertículo epifrénico. Cirugía Endoscópica 2010;11:32-5.

33. Hoshino M, Omura N, Yano F, Tsuboi K, Matsumoto A, Kashiwagi $\mathrm{H}$, et al. Laparoscopic Heller myotomy and Dor fundoplication combined with laparoscopic diverticular introversion suturing for achalasia complicated by epiphrenic diverticulum: report of a case. Surg Today 2010;40:158-61.

34. Pernazza G, Monsellato I, Pende V, Alfano G, Mazzocchi P, D'Annibale A. Fully robotic treatment of an epiphrenic diverticulum: report of a case. Minim Invasive Ther Allied Technol 2012;21:96-100.

35. Olarte P, Luis Padrón O, Arboleda D. Laparoscopic resection of epiphrenic diverticulum. Rev Colomb Cir 2012;27:306-13.

36. Fékéte F, Vonns C. Surgical management of esophageal thoracic diverticula. Hepatogastroenterology 1992;39:97-9.

38. Nehra D, Lord RV, DeMeester TR, Theisen J, Peters JH, Crookes PF, et al. Physiologic basis for the treatment of epiphrenic diverticulum. Ann Surg 2002;235:346-54.

39. Benacci JC, Deschamps C, Trastek VF, Allen MS, Daly RC, Pairolero PC. Epiphrenic diverticulum: results of surgical treatment. Ann Thorac Surg 1993;55:1109-13.

40. Streitz JM Jr, Glick ME, Ellis FH Jr. Selective use of myotomy for treatment of epiphrenic diverticula. Manometric and clinical analysis. Arch Surg 1992;127:585-7. 